\title{
Harmonics and Inter-Harmonics of Voltage Converter Supplied Induction Machine Stator Currents
}

\author{
Jan Rusek
}

\author{
Chair of Electrical Machines \\ AGH University of Science and Technology \\ Al. Mickiewicza 30, 30-059 Krakow (Poland) \\ phone: +48 126172897, fax: +48 126341096, e-mail: gerusek@cyf-kr.edu.pl
}

\begin{abstract}
The paper contains waveforms of currents for the direct and voltage source inverter supplied induction machine, with account for harmonics and inter-harmonics. By direct supply the grid is assumed to be either purely sinusoidal or polluted by $3^{\text {rd }}, 5^{\text {th }}$ and $7^{\text {th }}$ harmonics. The voltage inverter operates in a PWM mode. Special model of the machine accounts for true dependencies of stator and rotor inductances versus rotor angle, resulting from air gap magnetic flux distribution. Calculations of true derivatives of inductances, with respect to rotor angle, allowed for calculation of electromagnetic torque and, in consequence, the machine's dynamics, with allowance for speed fluctuation in steady state operation.
\end{abstract}

\section{Key words}

Poly-harmonic model, PWM, spectral composition of currents, inter-harmonics

\section{Introduction}

There are cases of so important drives that any break of propulsion should be avoided. These are the cases where heavy secondary or follow-up losses could arise from breaks in propulsion. The others, still worse cases, are those where propulsion breaks could threaten the environment or even humans. The possibilities of preventing such propulsion outages depend on the art of the equipment securing the propulsion. In many a case it will be a squirrel cage induction machine. Then the common cause for propulsion breaks is lack of voltage in power supply system, due to some emergency states followed by switching off the main power supply system. The usual healing procedure is to re-switch the supply on a stand-by power supply system. Due to many unpredictable reasons, also this system can fail or not be ready to overtake the power supply function. Then the next stage can be switching the supply on a stand-by power source such as a battery or diesel driven DC generator. Application of a static converter such as PWM voltage inverter is one of the common techniques of powering the induction machine. The additional advantage of this technique is natural possibility of speed adjustment via supply-voltage frequency control. Obviously, the supply-voltage frequency is here understood as the frequency of the fundamental harmonics of the supply voltages, common to all three phases. By the most widespread PWM mode of operating the voltage source inverter, the supply voltages are enormously deformed. In other words, it can be said that the higher voltage harmonics will heavily contribute to the total supply voltages. This, in turn, will lead to significant presence of higher harmonics in the stator and rotor currents. However, the relative contribution of current higher harmonics to the total current will be much smaller as compared to the voltage harmonics, as the machine's winding inductances act in a manner reminding low pass filter. In steady state operation, the frequencies of both the voltage and current higher harmonics result from properties of the PWM inverter and constant substitution inductance of the motor. Their frequencies do not depend on the current speed of the rotor. The latter solely effects their amplitudes.

However, these are not the only harmonics which contribute to the stator and rotor currents. The machine itself generates its own harmonics both in the stator and rotors circuits. The frequencies of these harmonics depend on rotor speed, which depend not only on the supply frequency but also on the loading torque. Such a type of harmonics is usually referred to as interharmonics.

If the stator windings are configured in delta, the stator phase voltages are forced or determined by the supply voltages. The higher harmonics of the electromotive forces would cause the flow of higher harmonics of the currents. The voltage drops across stator leakage inductances, caused by these harmonic currents, would cancel these harmonics of the electromotive forces. Delta configuration of the stator windings is only practical in low power machines. By high power machines, in particular by high voltage machines, the only practical configuration is wye. In this case only the phase-to-phase voltages are forced or determined by the supply voltages, not however the phase voltages. Hence, the by the machine itself induced electromotive forces in the stator phases can lead to deformation of the phase voltages. In consequence, the potential of the stator wye point is no longer neutral nor constant. This issue, however, falls beyond the scope of the present paper.

With respect to the rotor circuits, only the current harmonics are of interest, as only these harmonics can contribute (positively or adversely) to torque production. They, similarly as in the case of stator, contribute also to copper losses, as these depend on effective currents, depending in turn on both the harmonics and inter-harmonics.

The aim of the present paper is to calculate waveforms of stator phase and rotor bar currents for the 
voltage source inverter supplied squirrel cage induction machine, with account for both the harmonics and interharmonics. The voltage source inverter is assumed to operate in a PWM mode. The specially developed and implemented model of the machine accounts for true dependencies of stator and rotor inductances versus rotor angle, resulting from true magnetic flux distribution down the air gap peripheral. Only such a model, as opposed to fundamental harmonic model, allows for inclusion into calculations also inter-harmonics. Calculations of true derivatives of inductances, with respect to rotor angle, allowed for calculations of electromagnetic torque. This in turn allowed for calculation of machine's dynamics, with allowance for true speed variation during starting up and true speed fluctuation in steady state operation.

For the sake of completeness and reference basis, the calculations for directly supplied machine were also included, for both purely sinusoidal and polluted supply voltages.

After calculations of current waveforms, for a prolonged steady state operation, their spectral composition was established using FFT procedure. It reveals two types of harmonics. The first ones, the dominating ones, are those the frequencies of which are determined by the PWM converter. The others, the ones generated by the machine itself, are of much smaller amplitudes. Their frequencies depend on both the frequency generated by the PWM inverter and current loading of the machine, effecting rotor speed.

All the calculations refer to a $132 \mathrm{~kW}$, 4-pole, $1000 \mathrm{~V}, 50 \mathrm{~Hz}$ squirrel cage induction machine. The rotor inertia is $4.5 \mathrm{~kg} \mathrm{~m}^{2}$. In fact, it is a two-speed machine, with the other number of poles being 12 , but the present calculations refer to 4 poles only. All the parameters of the machine's magnetic circuit, stator winding distribution and rotor cage layout were taken over from machine's manufacturer.

\section{Machine supplied by sinusoidal voltages}

As stated in the previous paragraph, the ratings of the machine were: $1000 \mathrm{~V}, Y, 2 p=4$ poles, $P_{N}=132 \mathrm{~kW}$, $N_{S} / N_{R}=72 / 56$. The load characteristic consisted of small constant component of $55 \mathrm{Nm}$ and of quadratic component, amounting to $800 \mathrm{Nm}$ by rated synchronous speed. Fig. 1 shows the starting and steady state current, for the supply from a three-phase set of balanced, rated, sinusoidal voltages. Fig. 2 presents the spectrum of the steady state interval of the current. The presence of the first or fundamental $50 \mathrm{~Hz}$ component is obvious. The other harmonic seen in Fig. 2 is the so called slot interharmonic the frequency of which is $1433.3 \mathrm{~Hz}$. Its frequency depends on the speed. Actually, its frequency is highly sensitive to the speed. Hence, in some applications, it is being used to identify the rotor speed. One of such applications is diagnosing the state of the rotor cage, as here the knowledge of rotor speed with very high accuracy is of substantial importance. The amplitude of this component, here amounting to $-51.5 \mathrm{~dB}$ with respect to fundamental harmonic is sufficiently big for secure identification with contemporary analog-todigital converters, installable in portable computers.

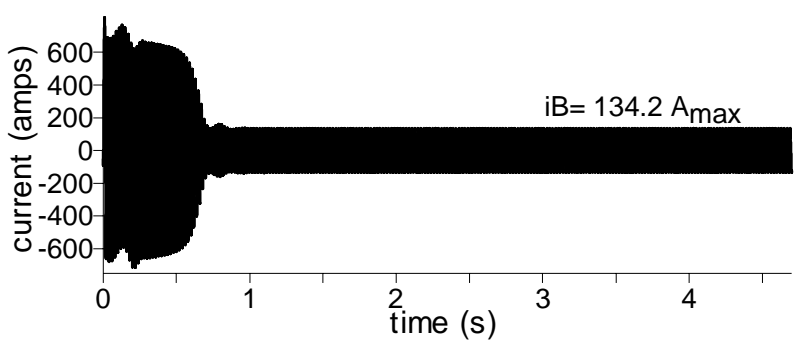

Fig.1. Current by purely sinusoidal supply voltages.

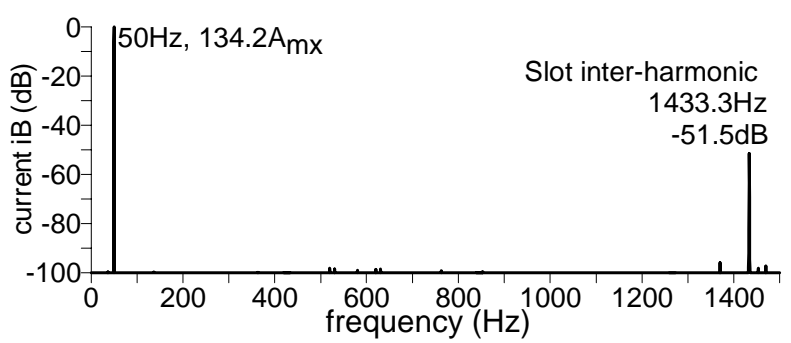

Fig.2. Spectrum of steady state current segment from 1.7 to 4.7 s. Frequency resolution $\Delta \mathrm{f}=0.333 \mathrm{~Hz}$.

\section{Machine supplied by deformed voltages: fundamental plus $3^{\text {rd }}, 5^{\text {th }}$ and $7^{\text {th }}$ harmonics}

Normally, the voltages of power supply system are not purely sinusoidal. It practically all measurements the presence of $3^{\text {rd }}, 5^{\text {th }}$ and $7^{\text {th }}$ harmonics, in addition o the fundamental or $50 \mathrm{~Hz}$ one, is confirmed.

Fig. 3 presents the current plot during starting up followed by a steady state, with account for higher harmonics in the supply voltages. Considering limited magnitudes of these harmonics, it is hardly possible to discern any difference between plots in Figs. 3 and 1. However, the spectrum presented in Fig. 4 reveals the presence of these harmonics in the supply currents. The other harmonic, also common in power systems, is that of $100 \mathrm{~Hz}$. However, this harmonic was not accounted for.

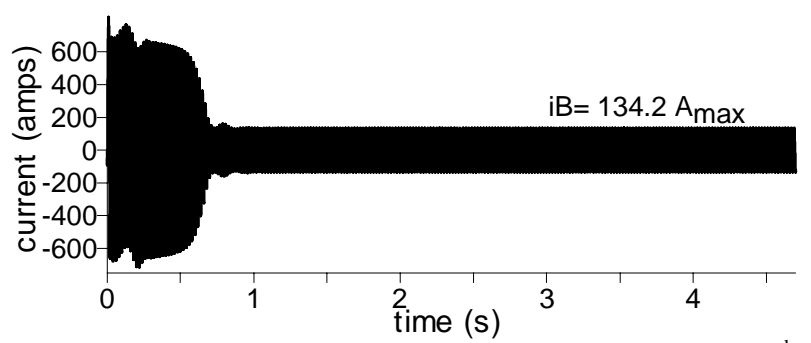

Fig. 3. Current by three-phase supply voltages polluted by $3^{\text {rd }}$, $5^{\text {th }}$ and $7^{\text {th }}$ harmonics.

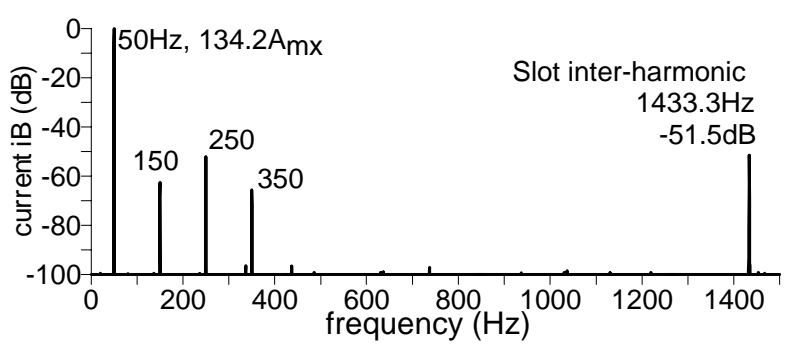

Fig. 4. Spectrum of steady state current segment from 1.7 to 4.7 s. Frequency resolution $\Delta \mathrm{f}=0.333 \mathrm{~Hz}$. 


\section{Machine supplied by PWM voltage inverter with $900 \mathrm{~Hz}$ carrier frequency}

The voltage inverter, operated in PWM mode, was assumed to operate with a rather low carrier frequency. The carrier wave, common to all three legs of the inverter, was assumed to be of saw-tooth shape, with symmetrical sides. Three symmetrical modulating waves are compared with the common carrier wave. Whenever the value of the modulating wave is bigger than that of the carrier wave the phase associated with the modulating wave is switched to the positive DC link voltage. And vice versa.

Voltage in Fig. 5 is a sum of voltage drops across the coils connected in series between machine's terminals B and C. DC link voltage was $1600 \mathrm{~V}$, carrier frequency $900 \mathrm{~Hz}$, amplitudes of $50 \mathrm{~Hz}$ symmetrical modulating waves were 0.9 with respect to the saw-tooth carrier wave common to all three modulating sinusoidal waves.

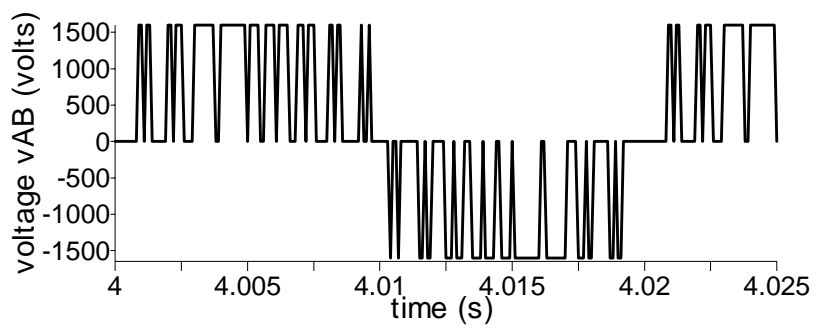

Fig.5. Voltages $\mathrm{V}_{\mathrm{BC}}$ for the case of PWM supplied machine.

Fig. 6 presents current waveform of the PWM fed machine, during direct start up by full frequency and full voltage. It follows from Fig. 6 that the current waveform is far less polluted that the voltage in Fig. 5. Nevertheless, spectral analysis reveals its complex harmonic composition. Fig. 7 presents spectrum of the current, including slot inter-harmonic. Of course the spectrum contains also slot inter-harmonic generated by the machine, and not by the inverter.

The same principle of operation was assumed for the PWM inverter operated with $40 \mathrm{~Hz}$. Fig. 8 presents spectrum of the current by $40 \mathrm{~Hz}$ modulating waves. The slot inter-harmonic is visible, with now lower frequency.

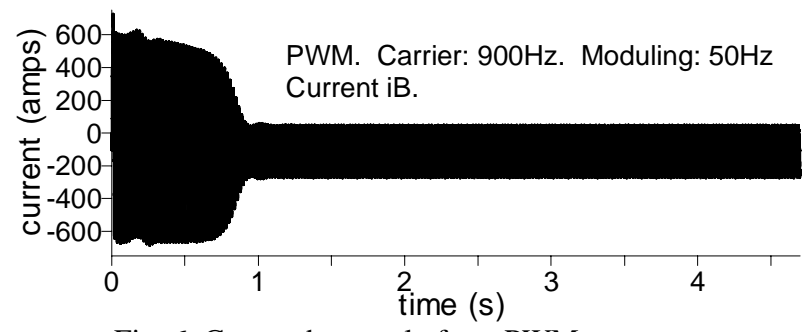

Fig. 6. Current by supply from PWM converter.

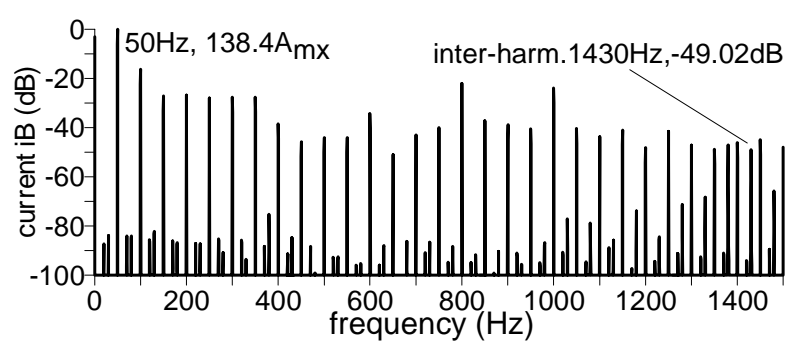

Fig. 7. Current spectrum by PWM, 50Hz, supply.

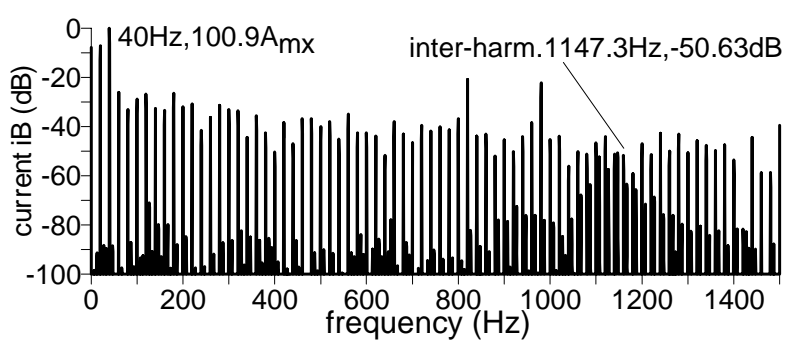

Fig. 8. Current spectrum by PWM, 40Hz, supply.

By $50 \mathrm{~Hz}$ modulating frequency, in Fig. 7 the frequencies of dominating spectral components are multiples of 50 $\mathrm{Hz}$ fundamental frequency. Contrary to this, by $40 \mathrm{~Hz}$ modulating frequency, in Fig. 8 the frequencies of dominating spectral components are multiples of $20 \mathrm{~Hz}$, and not only of $40 \mathrm{~Hz}$ fundamental.

\section{Machine supplied by PWM voltage inverter with $1800 \mathrm{~Hz}$ carrier frequency}

The supply conditions now differ from those in paragraph 4 only in that now the carrier frequency is $1800 \mathrm{~Hz}$.

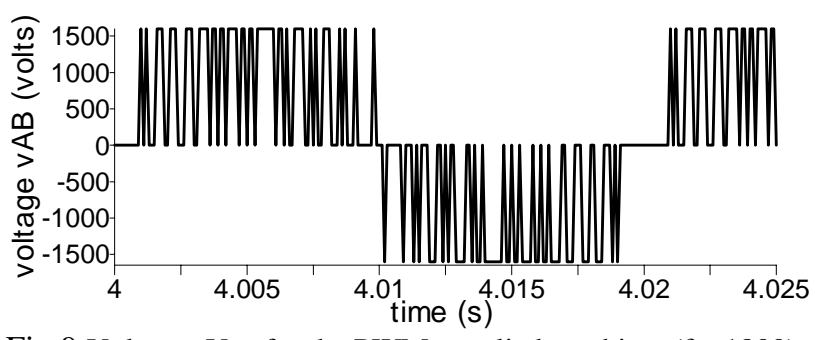

Fig.9 Voltages $V_{B C}$ for the PWM supplied machine. $\left(f_{C}=1800\right)$

The current plot in Fig. 10 is biased by a DC component, similarly as in Fig. 6. This is due to asymmetry of PWM inverter output voltage, by assumed modulation algorithm, where only one switch switches at a time. By $50 \mathrm{~Hz}$ modulating frequency, in Fig. 11 the frequencies of dominating spectral components are multiples of 50 $\mathrm{Hz}$ fundamental. By $40 \mathrm{~Hz}$ modulating frequency, in Fig. 12 the frequencies of dominating spectral components are spaced by $80 \mathrm{~Hz}$ from one another, starting at $40 \mathrm{~Hz}$.

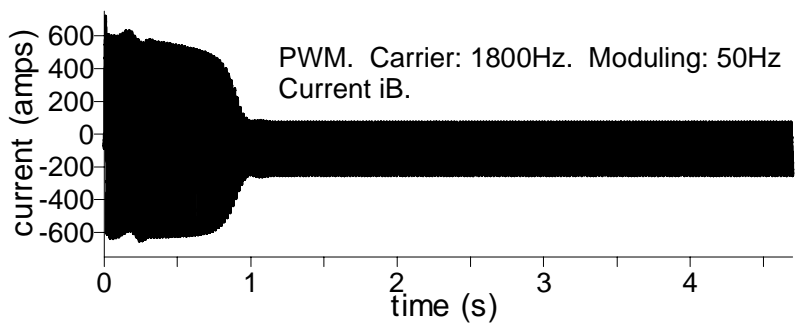

Fig.10. Current by supply from PWM converter.

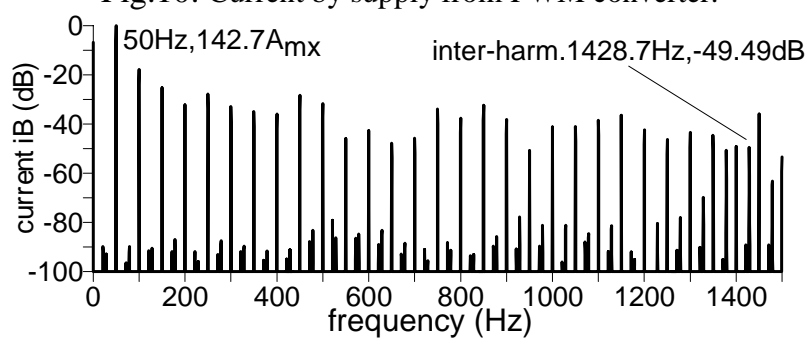

Fig.11. Current spectrum by PWM frequencies $\mathrm{f}_{C}=1800, \mathrm{f}_{\mathrm{M}}=50$ 


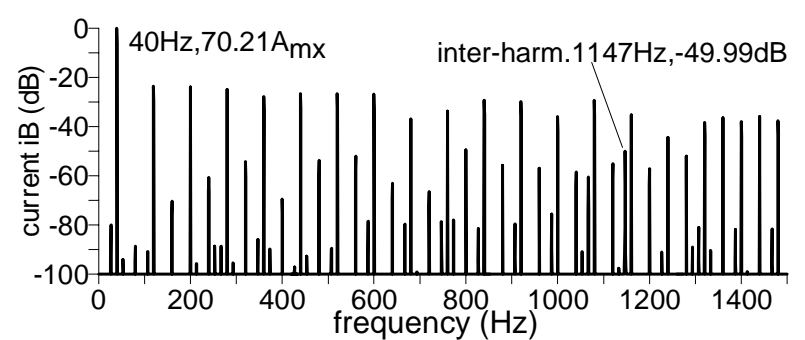

Fig.12. Current spectrum by PWM frequencies $\mathrm{f}_{C}=1800, \mathrm{f}_{\mathrm{M}}=40$

\section{Machine supplied by PWM voltage inverter with $5 \mathrm{kHz}$ carrier frequency}

The supply conditions differ from those in paragraph 4 only in that now the carrier frequency is $5000 \mathrm{~Hz}$. Magnified carrier frequency diminishes consequences of voltage asymmetries, due to the assumed modulating procedure. The DC component in the currents is practically absent. That reveals comparing Fig. 14 with Fig. 6 or 10. Another words, high carrier frequency damps DC components of the currents, resulting from voltage asymmetry due to assumed modulating procedure. In Fig. 15, the slot inter-harmonic is pretty well visible, though it no longer dominates over those generated by the inverter. Comparison of Fig. 15 with 7 or 11 reveals also that magnified carrier frequency leads to lowering of the amplitudes of the spectral components resulting from PWM inverter.

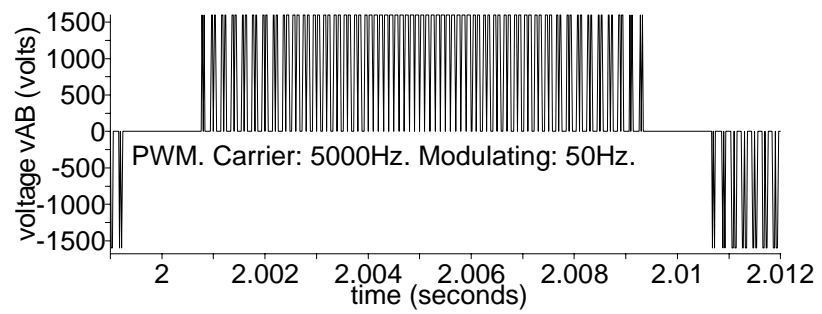

Fig.13 Voltages $\mathrm{V}_{\mathrm{BC}}$ for the PWM supplied machine $\left(\mathrm{f}_{\mathrm{C}}=5000\right)$

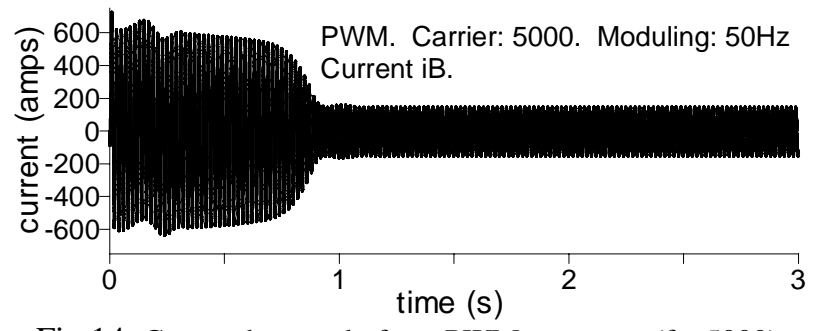

Fig.14. Current by supply from PWM converter $\left(f_{C}=5000\right)$.

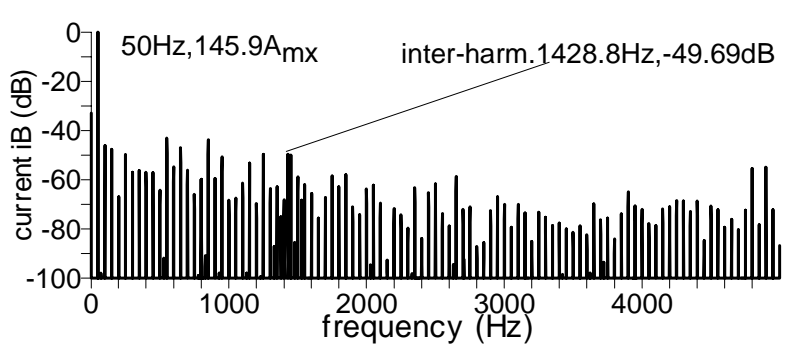

Fig. 15. Current spectrum by $P W M$ frequencies $\mathrm{f}_{C}=5000, \mathrm{f}_{\mathrm{M}}=50$

\section{Conclusions}

Generalization of the already existing model of the squirrel cage induction machine on PWM inverter supply allowed to include into calculations, apart of machine generated harmonics, also harmonics generated by the inverter. The spectrum of the current spectrum depends heavily on the ratio of the carrier and modulating frequencies.

The assumed algorithm of the modulation of voltages generated by an inverter allows the DC component to appear in the stator current of the induction motor. The magnitude of this component diminishes together with magnified frequency of the carrier wave. By $5 \mathrm{kHz}$ this component practically vanish.

\section{References}

[1] Rusek, J.: "Transients in a wind-mill driven, two-speed, squirrel-cage induction generator". ICREPQ'05, Zaragoza $16,17,18$ of March, 2005. Proceedings, pp. 19-20.

[2] Rusek, J.: "Interharmonics injected into power system by a squirrel-cage induction machine in normal and faulty operating conditions". ICREPQ'06, Mallorca, 5,6,7 of April, 2006. Book of summaries, pp.59-60.

[3] Rusek J.: "Interharmonics generated by induction machines" XLII International Symposium on El. Machines SME 2006, Cracow, July 3-6, 2006, Proceedings, pp. 159-162.

[4] ] Nylkinski, A., Rams, W., Rusek, J.: "Measurement and Calculation of Voltages Induced in Non-Supplied Winding of Double Speed Induction Motors". XLII International Symposium on El. Machines SME 2006, Cracow, July 3-6, 2006, Proceedings, pp. 271-274.

\section{Acknowledgement}

This work was supported by AGH University of Science and Technology Statute Work number 11.11.120.608. 